ORIGINAL ARTICLE

\title{
Withholding life prolonging treatment, and self deception
}

\author{
G M Sayers, S Perera
}

J Med Ethics 2002;28:347-352

See end of article for authors' affiliations

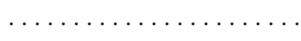

Correspondence to: Dr G M Sayers,

Department of Geriatric and General Medicine, Northwick Park Hospital, Watford Road, Harrow, Middlesex HAl 3UJ, UK; gwen.sayers@ic.ac.uk
Objectives: To compare non-treatment decision making by general practitioners and geriatricians in response to vignettes. To see whether the doctors' decisions were informed by ethical or legal reasoning.

Design: Qualitative study in which consultant geriatricians and general practitioners (GPs) randomly selected from a list of local practitioners were interviewed. The doctors were asked whether patients described in five vignettes should be admitted to hospital for further care, and to give supporting reasons. They were asked with whom they would consult, who they believed ought to make such decisions, and whether the relatives' preferences would influence their decision making.

Main measures: To analyse the factors influencing the doctors' decisions not to admit otherwise terminally ill patients to hospital for life prolonging treatment.

Results: Seventeen GPs and 18 geriatricians completed the interview. All vignettes produced strong concordance in decision making between both groups. Ten per cent of the doctors would provide life prolonging treatment to patients with severe brain damage. Most would admit a surgical patient regardless of age or disability. Medical reasons were largely used to explain decision making. The wishes of relatives were influential and resource considerations were not. There was variability regarding decision making responsibility.

Conclusions: Little attempt was made to link decision making with ethical or legal concepts and there may have been non-recognition, or denial, of the ethical consequences of failure to admit. The process of decision making may involve deception. This may be conscious, because of the illegality of euthanasia, or unconscious (self deception), because of deepseated medical and societal reluctance to accept that intentionally withholding life prolonging treatment may equate with intentionally causing death.
$\mathrm{D}$ octors decide daily whether to treat patients and what treatment to administer. Such treatment aims, ordinarily, to cure the ailment or, when this is not possible, to ameliorate the symptoms.

A different type of decision making takes place when treatment is withheld or withdrawn allowing death to occur. The assumption is that further life prolonging treatment will not benefit the patient. As death is necessarily a consequence, it follows that the doctor also considers that the patient will not benefit from further length of life. Hence an intention of such decision making may be the death of the patient.

This apparent medical collusion with death needs to be squared with medical, societal, and legal values, many of which arise from the special value accorded to life as such. Denying that death is an intention of non-treatment achieves this. Such denial derives partly from the law that prohibits intentional termination of life, partly from some forms of ethical reasoning, and partly from doctors' values, which mirror those of society.

The result has been the evolution of a medical, ethical, and legal matrix, which attempts to justify medical actions or non-actions that result in death. This justificatory framework is constantly remoulded, as it is imperfect. Some arguments appear flawed because they seem, consciously or unconsciously, to bend the truth.

For example, take the broad statement that: "Although the (doctor) may foresee that withholding or withdrawing life prolonging treatment will result in the patient's death, this is fundamentally different from action taken with the purpose or objective of ending the patient's life" ${ }^{\prime}{ }^{1}$ It could contrarily be argued that death resulting from withholding treatment could, in some cases, be both foreseen and intended; and that withdrawing life prolonging treatment is morally equivalent to action taken with the purpose of ending the patient's life.
This study set out to explore the reasons doctors give for non-treatment decisions that will probably result in the death of patients. We were particularly interested in whether ethical and legal reasoning informed decision making.

We looked at withholding life prolonging treatment, since this is more common than withdrawal of such treatment. The circumstances are usually less clear cut and thus less likely to receive legal attention in the $U \mathrm{UK}^{2}$ It is claimed that with some conditions, such as advanced dementia and severe stroke, a practice of withholding life prolonging treatment has developed in this country. ${ }^{3}$ Little is known, however, about what actually occurs, or the reasoning used by doctors to support their decision to withhold treatment.

Ethical practice is variable, as demonstrated by the poor consensus in decision making by clinical ethicists when asked whether to recommend life prolonging treatment in hypothetical vignettes. ${ }^{4}$ Thus we decided to compare decision making by two different groups of doctors.

The doctors' decision making was analysed by using five vignettes, in all of which the patient, if treated in hospital, would probably have lived longer. This accords with the understanding that British nursing homes do not have provision for intravenous hydration, intravenous antibiotic administration, or nasogastric feeding. Hence in ethical terms, nonadmission of any of the patients could be viewed as "letting die" or "passive euthanasia".

\section{METHODS}

Twenty general practitioners (GPs) working in Harrow were randomly selected and 17 who consented to participate in the study were interviewed by Suni Perera. Gwen Sayers interviewed the three geriatricians who were based in Harrow and 15 other geriatricians known to her. 


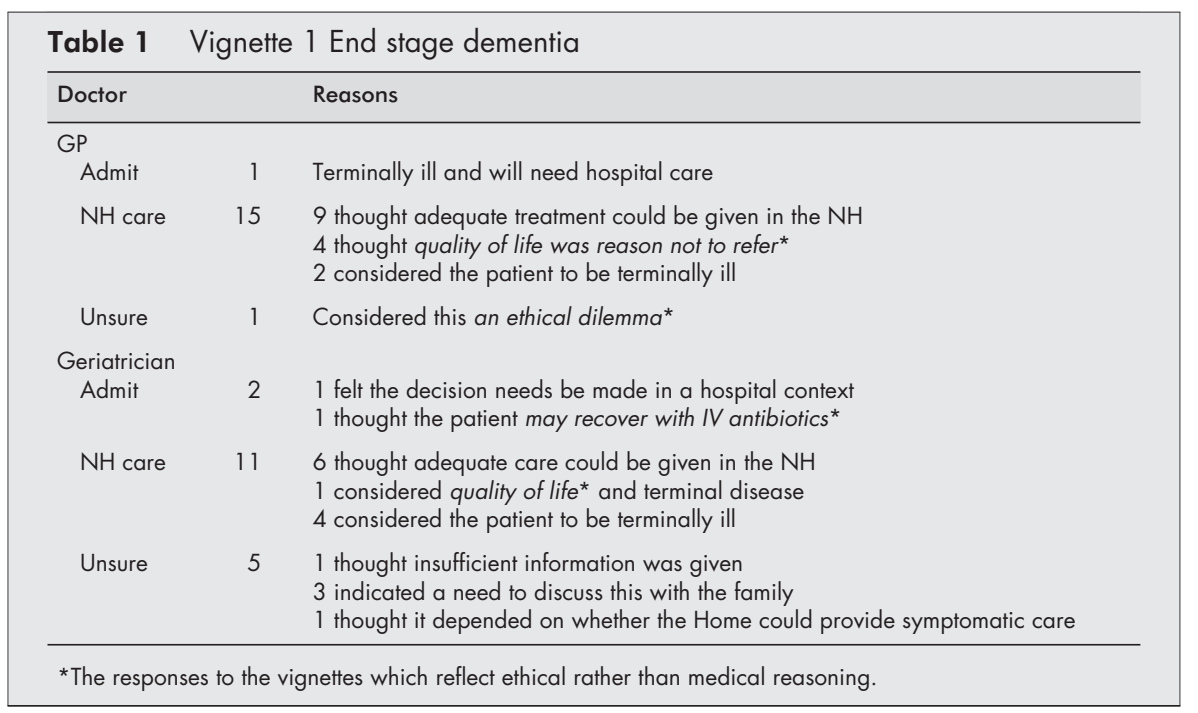

\begin{tabular}{|c|c|c|}
\hline Doctor & & Reasons \\
\hline \multicolumn{3}{|l|}{ GP } \\
\hline Admit & 12 & $\begin{array}{l}6 \text { for hydration and feeding* } \\
4 \text { because this required specific hospital management } \\
1 \text { did not specify } \\
1 \text { because the patient would be in distress* }\end{array}$ \\
\hline NH care & 3 & $\begin{array}{l}1 \text { felt it unnecessary to admit but would ask a geriatrician } \\
1 \text { would first give conservative treatment and see how he does } \\
1 \text { would offer food and fluids but only offer admission if the patient wanted it* }\end{array}$ \\
\hline Unsure & 2 & $\begin{array}{l}1 \text { thought it a matter of nourishment*, and considered the possibility of media } \\
\text { attacks } \\
1 \text { thought this was a difficult one and needed to discuss with the family, but would } \\
\text { not want to admit }\end{array}$ \\
\hline \multicolumn{3}{|l|}{ Geriatrician } \\
\hline Admit & 10 & $\begin{array}{l}6 \text { would admit for feeding* } \\
3 \text { would admit for medical treatment } \\
1 \text { would admit for feeding* and treatment }\end{array}$ \\
\hline $\mathrm{NH}$ care & 3 & Nothing further can be done for the patient \\
\hline Unsure & 5 & $\begin{array}{l}4 \text { thought not enough information was provided } \\
1 \text { wanted the relatives' views }\end{array}$ \\
\hline
\end{tabular}

The doctors were initially asked: "Which of the following nursing home patients do you think should be referred to hospital for admission"?

1. A patient with end stage dementia (immobile, doubly incontinent and non-communicative) who develops severe pneumonia.

2. A patient with end stage Parkinson's disease (immobile, requiring an apomorphine pump and help with all activities of daily living) who develops dysphagia and inadequate oral intake.

3. A 97 year old arteriopath (bilateral amputee) who develops an acute abdomen.

4. A patient bed bound from previous strokes, who is found comatose with a new stroke.

5. A patient with terminal prostatic cancer who develops septicaemia secondary to a urinary tract infection.

With the presentation of each vignette, they were asked for the reasons why they made their decision.

They were then asked with whom they would discuss a decision not to refer to hospital.
They were asked who they thought should make such a decision.

Finally, they were asked whether a relative's preference for hospital treatment would influence their decision not to admit.

\section{RESULTS}

These are tabulated in tables 1 to 9 .

The pattern of decision making is very similar when comparing the responses made by the two doctor groups to vignettes one, two, and four. In vignette five, where there is less individual concordance, there is nevertheless a similar pattern of distribution when comparing the two doctor groups. Except for vignette three, where all the GPs would admit the patient, the category of doctor did not determine the type of decision made. Neither did the doctor category determine the people with whom the doctor would consult when deciding not to admit, the family members being the most preferred.

The geriatricians were more inclined to view the doctor as the person who should make the decision not to admit, with almost all the GPs relying on some form of joint decision making. 


\begin{tabular}{|c|c|c|}
\hline Doctor & & Reasons \\
\hline \multicolumn{3}{|l|}{ GP } \\
\hline Admit & 17 & $\begin{array}{l}8 \text { thought the patient required hospital treatment } \\
6 \text { thought the patient required a diagnosis } \\
1 \text { thought the patient required a diagnosis and treatment } \\
1 \text { wanted admission for relief of patient distress } \\
1 \text { did not want to admit the patient because of age* but felt "unable to sit on an } \\
\text { acute abdomen" }\end{array}$ \\
\hline $\mathrm{NH}$ care & $\begin{array}{l}0 \\
0\end{array}$ & \\
\hline \multicolumn{3}{|l|}{ Geriatrician } \\
\hline Admit & 13 & $\begin{array}{l}5 \text { would admit for diagnostic reasons } \\
6 \text { would admit for treatment } \\
1 \text { would admit for pain control } \\
1 \text { considered it to be a surgical emergency and felt that not admitting would equate } \\
\text { to euthanasia* }\end{array}$ \\
\hline $\mathrm{NH}$ care & 2 & $\begin{array}{l}1 \text { felt the surgical risk was too high } \\
1 \text { knew the surgeons would not operate }\end{array}$ \\
\hline Unsure & 3 & $\begin{array}{l}2 \text { felt inadequate information was provided } \\
1 \text { felt it was up to the patient* }\end{array}$ \\
\hline
\end{tabular}

*The responses to the vignettes which reflect ethical rather than medical reasoning.

\begin{tabular}{|c|c|c|}
\hline Doctor & & Reasons \\
\hline \multicolumn{3}{|l|}{ GP } \\
\hline Admit & 1 & Because of comatose state \\
\hline $\mathrm{NH}$ care & 15 & $\begin{array}{l}7 \text { because the hospital could offer no more than the } \mathrm{NH} \\
1 \text { thought the } \mathrm{NH} \text { could provide better care } \\
1 \text { provided the } \mathrm{NH} \text { could cope } \\
1 \text { provided the } \mathrm{NH} \text { could cope and the relatives were consulted } \\
2 \text { depending on what the relatives wanted } \\
1 \text { because of poor prognosis } \\
1 \text { after home visit by geriatrician } \\
1 \text { would not admit but see how things progressed }\end{array}$ \\
\hline Unsure & 1 & Not enough information provided \\
\hline \multicolumn{3}{|l|}{ Geriatrician } \\
\hline Admit & 3 & $\begin{array}{l}1 \text { would admit unless the family wanted otherwise } \\
1 \text { because "all strokes need to be assessed in hospital" } \\
1 \text { thought that "bed bound" does not necessarily equate with a poor quality of life* }\end{array}$ \\
\hline $\mathrm{NH}$ care & 11 & $\begin{array}{l}9 \text { because the hospital could offer no more than the } \mathrm{NH} \\
1 \text { would reconsider if the patient woke up } \\
1 \text { provided the } \mathrm{NH} \text { could cope with symptom control }\end{array}$ \\
\hline Unsure & 4 & $\begin{array}{l}2 \text { because not enough information was provided } \\
2 \text { because they needed to talk to others }\end{array}$ \\
\hline
\end{tabular}

Almost all the doctors said they would allow the relative's preference to influence their decision making, although nearly half of the geriatricians indicated that it would not change their decision.

\section{ANALYSING THE RESULTS}

Vignettes one and four are examples of the circumstances where it is thought that many doctors would refrain from life prolonging treatment. As only three of the 35 doctors would admit the demented patient and four would admit the comatose patient, our findings support this supposition. This is relevant, since in the UK the Bolam test influences the courts. This standard deems practice acceptable if in accordance with a responsible body of medical opinion. ${ }^{6}$ In considering the case of Tony Bland, Lord Goff said: "A medical practitioner is under no duty to continue to treat a patient where a large body of informed and responsible medical opinion is to the effect that no benefit at all would be conferred by continuance". ${ }^{7}$

Withholding life prolonging treatment is, however, a moral rather than a medical decision, and as such cannot be based on the number of people who subscribe to the view. Hence Lord Mustill's judgment that: "There is no reason in logic why on such an (ethical) decision the opinions of doctors should be decisive ${ }^{\prime \prime}{ }^{8}$

Few of the doctors provided "ethical" reasons to support their decision making. Five doctors cited quality of life considerations in the case of the demented patient, and one doctor thought that being bed bound, in the case of the stroke patient, did not necessarily equate with a poor quality of life. Only one doctor considered a vignette to be an "ethical dilemma". 
Table 5 Vignette 5 Terminal prostatic cancer with septicaemia

\begin{tabular}{|c|c|c|}
\hline Doctor & & Reasons \\
\hline \multicolumn{3}{|l|}{ GP } \\
\hline Admit & 8 & $\begin{array}{l}5 \text { thought the patient was treatable } \\
1 \text { said it depended on the premorbid state } \\
1 \text { did not specify } \\
1 \text { thought it depended on how terminal the patient was but would only not admit it } \\
\text { they were previously unconscious }\end{array}$ \\
\hline $\mathrm{NH}$ care & 5 & $\begin{array}{l}2 \text { because of the terminal nature of the disease } \\
1 \text { because the patient could be treated in the } \mathrm{NH} \\
1 \text { would first try to treat in the } \mathrm{NH} \text { but if the patient deteriorated may decide to } \\
\text { admit } \\
1 \text { would treat in } \mathrm{NH} \text {. May ring someone for advice if no improvement. }\end{array}$ \\
\hline Unsure & 4 & $\begin{array}{l}2 \text { because it depended on what the relatives wanted } \\
1 \text { because it depended on what the patient wanted and how terminal he was } \\
1 \text { because it depended on how advanced the cancer was }\end{array}$ \\
\hline \multicolumn{3}{|l|}{ Geriatrician } \\
\hline Admit & 6 & All said septicaemia is reversible with IV antibiotics \\
\hline $\mathrm{NH}$ care & 7 & $\begin{array}{l}3 \text { because the patient is terminally ill } \\
2 \text { because treatment could be provided in the } \mathrm{NH} \\
1 \text { provided IV antibiotics could be administered in the } \mathrm{NH} \\
1 \text { because there was an argument for him to be kept comfortable* }\end{array}$ \\
\hline Unsure & 5 & $\begin{array}{l}2 \text { because not enough information was provided } \\
2 \text { because they were unclear as to how terminal the patient was } \\
1 \text { because there is no blanket rule* }\end{array}$ \\
\hline
\end{tabular}

Table 6 Pattern of decision making comparing both doctor groups

\begin{tabular}{lllll}
\hline Vignette & Doctor & Admit & NH care & Unsure \\
\hline Vignette 1 & GP & 1 & 15 & 1 \\
Dementia/pneumonia & Geriatrician & 2 & 11 & 5 \\
Vignette 2 & GP & 12 & 3 & 2 \\
Parkinson's/dysphagia & Geriatrician & 10 & 3 & 5 \\
Vignette 3 & GP & 17 & & \\
Acute abdomen & Geriatrician & 13 & 2 & 3 \\
Vignette 4 & GP & 1 & 15 & 1 \\
Stroke/comatose & Geriatrician & 3 & 11 & 4 \\
Vignette 5 & GP & 8 & 5 & 4 \\
Terminal cancer & Geriatrician & 6 & 7 & 5 \\
\hline
\end{tabular}

\begin{tabular}{|c|c|c|c|c|}
\hline & Family member & Patient & Another doctor & $\mathrm{NH}$ carers \\
\hline GP & 16 & 9 & 11 & 15 \\
\hline Geriatrician & 15 & 10 & 10 & 14 \\
\hline$\%$ of both doctor groups & $89 \%$ & $54 \%$ & $60 \%$ & $83 \%$ \\
\hline
\end{tabular}

What is striking about the doctors' reasoning is their reliance on medical matters. The reasons given were largely set in terms of treatment and palliative care. There was no express acknowledgement of outcome, nor use of terms such as "best interests".

Twenty two of the doctors would admit the patient with Parkinson's disease and dysphagia, largely to provide hydration or feeding. Some may have been influenced by the case of a GP who was investigated by the General Medical Council for serious professional misconduct. At the request of her daugh- ters, he ordered nurses to discontinue supplementary feeding for an elderly patient with Parkinson's disease, stroke, and dementia, who was immobile and unable to speak. ${ }^{9}$

The provision of feeding did not, however, influence decision making in the patient found comatose. Hence, feeding or hydration alone was not perceived to be a necessary reason for admission.

Thirty of the doctors would admit the patient with an acute abdomen. One doctor thought that: "not admitting (this patient) would equate to euthanasia", yet morally, it can be 
Table 8 Who should make the decision not to admit?

\begin{tabular}{|c|c|c|c|c|c|c|c|c|}
\hline & Joint & Doctor & $\begin{array}{l}\mathrm{Dr}+ \\
\text { relatives }\end{array}$ & $\begin{array}{l}\mathrm{Dr}+ \\
\text { carers }\end{array}$ & Relatives & $\begin{array}{l}\text { Patient or } \\
\text { relatives }\end{array}$ & $\begin{array}{l}\mathrm{Dr}+ \\
\text { patient }\end{array}$ & Courts \\
\hline GP & 9 & 1 & 3 & 1 & 1 & 1 & 1 & \\
\hline Geriatrician & 6 & 8 & 1 & 2 & & & & 1 \\
\hline
\end{tabular}

Table 9 Would the relatives' preference for hospital treatment influence a decision not to admit?

\begin{tabular}{llll}
\hline Ges & No & Qualified \\
\hline Geriatrician & 14 & 1 & $\begin{array}{l}1 \text { said it may do } \\
1 \text { said that medicolegally it would have to. }\end{array}$ \\
& 9 & 2 & $\begin{array}{l}6 \text { said it would influence but not change their decision. } \\
\text { They felt they could explain to the relatives the benefit of } \\
\text { not admitting the patient to hospital } \\
1 \text { said it would probably influence the decision }\end{array}$ \\
\hline
\end{tabular}

argued that not admitting any of the patients would be the equivalent. Only one doctor expressly took advanced age into account. This vignette highlights a limitation of the study, in that some doctors may have chosen to admit the patient for palliative care such as pain control, rather than for surgery or life prolonging treatment. The same limitation may apply to some responses given to other vignettes.

Fourteen of the doctors would admit the patient with terminal cancer. The main reason given was that septicaemia was treatable. There is good reason to suppose, however, that pneumonia in the demented patient would respond as well to intravenous antibiotics as septicaemia in the patient with terminal cancer. Yet the doctors were more inclined to view the demented patient as terminally ill, rather than to view the "terminal" patient as terminally ill.

Although the cognitive state of the patients in all the vignettes was deliberately omitted, there would be an assumption that the patient with cancer was mentally intact. Thus the difference in the doctors' responses to these two vignettes may hinge on the presence or absence of "personhood", but they did not make this explicit.

Limited National Health Service (NHS) resources were not cited by any of the doctors as a reason for withholding life prolonging treatment.

Few of the doctors would not be influenced by the relatives' wishes, although the law puts the decision making squarely in the doctor's court. Those doctors interested in the relatives' views were not concerned with what the patients may have wanted for themselves, but with what the relatives wished the patients' treatment to be. Even in the vignettes where the competence of the patient was not an issue, some doctors still chose to explore the views of family members, rather than those of the patient.

Veatch has proposed a principle of limited familial autonomy. ${ }^{10}$ Accordingly, the family would be presumed guardian unless their decision making was clearly perceived as unreasonable. This is what appears to have happened informally, and possibly unlawfully, within the context of the study.

\section{SELF DECEPTION AND THE INTERACTION BETWEEN MEDICINE AND LAW}

The law permits or prohibits certain actions. Under English law, another adult cannot serve as proxy, either to consent or dissent from treatment considered by doctors to be in the best interest of an incompetent patient. ${ }^{11}$ Defining the "best interest" of the patient is, however, complex and open to argument. In broad terms, if treatment or non-treatment, as determined by a doctor, is in the "best interests" of a patient, it is lawful.

English law also prohibits intentionally causing death. Thus: "In law, a doctor may foresee-be able to predict-that the patient will die if treatment is not provided but this cannot be the sole reason for not providing it; the overriding purpose or objective is to ensure that treatment which is not in the best interests of the patient is avoided. It is only when this condition is satisfied that withholding or withdrawing treatment without the patient's consent will be lawful."

Analogously, the casuists believed that any act affording sexual pleasure was a sin. Hence: "intercourse between spouses had to be directed by the intention to procreate and not by desire, lest it be an occasion of $\sin ^{\prime \prime} .{ }^{12}$ It may not be possible, however, to separate reasons for actions in this manner, but it may be possible for people knowingly to deceive others of their real intention. They may also, unknowingly, convince themselves that their reason for an action is other than the true reason. This is self deception.

Self deception seems to be motivated by desires or fears of the agent, ${ }^{13}$ and may serve the purpose of reducing anxiety. ${ }^{14}$ Thus we suggest that the doctor has an anxious desire not to cause death intentionally, and the lawyer has an anxious desire not to be party to the intentional causing of death.

"One very common form of self deceptive belief, involves believing that one's motive for doing something is other than the real motive. The motive that one attributes to oneself is a motive that is generally considered nobler than one's real motive." ${ }^{15}$

Davidson suggests that if a person says: "I am poisoning Charles because I want to save him pain", the person may err about his reason, particularly when there are two reasons for an action, of which one is pleasing and the other not. Here, the person may want to save Charles pain, but may also want him out of the way. ${ }^{16}$

An interplay of conflicting motives is seen in the judgments pertaining to Tony Bland. Lord Goff said: "The question is not whether the doctor should take a course which will kill his patient, or even take a course which has the effect of accelerating his death. The question is whether the doctor should or should not continue to provide his patient with medical treatment or care which, if continued, will prolong his patient's life." ${ }^{17}$

By contrast Lord Browne-Wilkinson said: "The whole purpose of stopping feeding is to bring about the death of Tony 
Bland". ${ }^{18}$ Lord Mustill echoed this in saying: "As I understand the position, (the doctors) have taken the ethical decision that it is better from every point of view that Tony Bland's life should be brought to an end". ${ }^{19}$ Lord Lowry talked of: "a distinction without a difference: the intention is to terminate life, but the acceptable way of doing so is to discontinue a regime which the law has said the doctors have no duty or even right to continue".$^{20}$

Barnes submits four conditions that need to be met for self deception to be present, ${ }^{21}$ and these conditions can be applied to non-treatment decision making:

1. The doctor has an anxious desire not to intend the death of a patient. This causes the doctor to believe that the patient's death is not intended, and to believe something else, which is the intention not to provide non-beneficial treatment.

2. The purpose of believing in the non-provision of nonbeneficial treatment is to reduce the anxiety that the death is intended.

3. The doctor is not intentionally biased or partial.

4. The doctor fails to make a high enough estimate of the causal role that the anxious desire not to intend death plays, in acquiring the belief that he or she is only intending not to provide non-beneficial treatment.

To intentionally seek reasons or evidence that will reduce one's anxiety is not, however, to self deceive; self deception only occurs when the four conditions are met. ${ }^{22}$

It is therefore possible that, like Lord Browne-Wilkinson as cited above, some doctors acknowledge that not providing treatment will cause death which is intended, and that intending death is acceptable in the circumstances. They may, nevertheless, intentionally seek other reasons to justify non-treatment and reduce anxiety.

The doctors in our study seem to escape these considerations altogether, by couching their decision making in non-ethical terms, and relying on literal interpretations of the medical situations depicted in the vignettes. So doing may in itself, however, be a form of either deception or self deception.

By setting the reasons for their non-treatment decisions in medical terms our doctors differ from Dutch doctors who were interviewed about their own "real" non-treatment decisions. They cited needless prolongation of life, low quality of life, undignified dying, and medical futility as reasons supporting their decision making. When questioned about intention, most acknowledged that death would be hastened, and some made the decision partly to hasten death. ${ }^{23}$

\section{CONCLUSION}

This study shows doctors of different disciplines making remarkably similar decisions when faced with five medical vignettes, in all of which a decision not to admit to hospital would probably result in the death of the patient depicted. The doctors gave medical rather than ethical reasons for their decisions, and the reasons were not applied consistently. By cloaking their reasoning in medical terms they avoided having to justify the outcome or death of the patient.

Withholding life prolonging treatment was previously recognised as passive euthanasia. In a BMA publication entitled Euthanasia, it was written: "Passive euthanasia tends to be used to describe the withdrawal or withholding of some necessary treatment for the maintenance of human life. We shall use the phrases 'a decision not to prolong life' or a 'non-treatment decision'". ${ }^{24}$ Such terminological tinkering may reduce anxiety, but euphemism alters meaning.
Lord Mustill abstained from debating whether withdrawing feeding from Tony Bland amounted to euthanasia but conceded that: "However much the terminologies may differ the ethical status of the two courses of action is for all relevant purposes indistinguishable". ${ }^{25}$ Lord Lowry went further in saying: "Might it not be suggested, no doubt quite wrongly, that this case is, in effect if not in law, an example of euthanasia in action"? ?26

In the UK an evolving ethical and legal framework provides justifications for withholding life prolonging treatment from some seriously ill patients, and may thus validate what some doctors appear to do intuitively. But the validation, which may be flawed, is provided at the expense of disguising the real issue, which is the "legitimacy" of passive euthanasia.

\section{ACKNOWLEDGEMENTS}

We thank our colleagues who so kindly gave of their time and views, as well as two anonymous assessors whose comments were immensely helpful.

\section{Authors' affiliations}

G M Sayers, Imperial College School of Medicine and Department of Geriatric and General Medicine, Northwick Park Hospital, Harrow, UK S Perera, The Village Surgery, Harrow, UK

\section{REFERENCES}

1 British Medical Association. Withholding and withdrawing life prolonging medical treatment: guidance for decision making. London: BMU Books, 2001: 58

2 Sayers GM. Dementia, indeterminacy and non-treatment. Bulletin of Medical Ethics 1994;103:13-16.

3 See reference 1: vii.

4 Fox E, Stocking C. Ethics consultants' recommendations for life prolonging treatment of patients in a persistent vegetative state. Journal of the American Medical Association 1993:270:2578-82.

5 Severe pneumonia is life threatening and is ordinarily treated in hospital with intravenous antibiotics and oxygen. Dysphagia is inability to swallow, and inadequate oral intake would result in death through dehydration or starvation. Arteriopathy, or generalised vascular disease, resulted in the loss of this patient's legs. An acute abdomen is usually due to obstruction, perforation, or (most likely in this patient) inadequate blood supply to the bowel. Without surgery, death of the patient is inevitable. A comatose patient, if untreated with nasogastric or intravenous fluids, would invariably die of dehydration. Septicaemia is a life threatening bacterial infection within the blood stream that requires treatment with intravenous antibiotics.

6 Bolam v Friern Hospital Management Committee [1957] 1 WLR 582.

7 Airedale NHS Trust $v$ Bland [1993] 2WLR 362D-E.

8 See reference 7: $399 \mathrm{H}$.

9 Dyer C. Withdrawal of food supplement judged as misconduct. British Medical Journal 1999;318:895.

10 Veatch RM. An ethical framework for terminal care decisions: a new classification of patients. Journal of the American Geriatrics Society 1984;32:665-9.

$11 \mathrm{~F}$ (Mental Patient; Sterilisation) [1989] 2WLR 1025.

12 Jonsen AR, Toulmin S. The abuse of casuistry: a history of moral reasoning. Berkeley: University of California Press, 1988: 179.

13 Mele AR. Self deception. The Philosophical Quarterly 1983;33:365-77

14 Barnes A. Seeing through self deception. Cambridge: Cambridge University Press. 1997: 35

15 See reference 14: 56 .

16 Davidson D. Essays on actions and events. Oxford: Oxford University Press, 1982: 18

17 See reference 7: 371A-B

18 See reference $7: 383 E$.

19 See reference $7: 389 \mathrm{~F}$

20 See reference 7: 379F.

21 See reference 14: 117

22 See reference 14: 124

23 Van Thiel GJMW, van Delden JJM, de Haan K, et al. Retrospective study of doctors' "end of life decisions" in caring for mentally handicapped people in institutions in the Netherlands. British Medical Journal 1997;315:88-91.

24 British Medical Association. Euthanasia. London: British Medical Association, 1988: 3 .

25 See reference 7: $388 \mathrm{H}$

26 See reference 7: $379 \mathrm{G}$ 